\title{
Food innovation and entrepreneurship in higher education: a case study
}

\author{
Susana C. Fonseca ${ }^{a *}$, Rita Pinheiro ${ }^{a}$, Carla Barbosa ${ }^{a}$, Alberta Araújo $^{a}$, \\ Manuela Vaz-Velho ${ }^{a}$, And Rui Alves ${ }^{a}$ \\ ${ }^{\text {a }}$ Instituto Politécnico de Viana do Castelo, Escola Superior de Tecnologia e Gestão, Av. Atlântico, 4900-348 \\ Viana do Castelo, Portugal \\ ${ }^{*}$ Corresponding author \\ scfonseca@estg.ipvc.pt \\ TEL: +351258 819700 \\ FAX: +351258827636 \\ Received: 5 July 2014; Published online: 18 October 2015 \\ Invited paper from the $3^{\text {rd }}$ International ISEKI_Food Conference - ISEKI_Food 2014 - Bridging Training and \\ Research for Industry and the Wider Community - Food Science and Technology Excellence for a Sustainable \\ Bioeconomy
}

\begin{abstract}
Food innovation and entrepreneurship are important topics in graduate food studies. Students should be challenged to promote an innovative attitude towards their future career in the food industry sector, as professionals working in a small and medium-sized enterprise, or in a large multinational company, or even as entrepreneurs with their own working projects. The present case study shows a curricular unit of a master course that intends to integrate the knowledge on new and sustainable technologies and products, based on seminars of experts on hot topics, on visits to food industry enterprises and market expositions and on the development of a state-of-the-art report about an emergent or novel food technology or product with oral presentation. Hot topic seminars included edible coatings, bioprocessing, allying tradition and innovation in food products, new convenience foods, challenging tests, and new clean and sustainable processes. Entrepreneur alumni lectures were also promoted allowing exchange of experiences. Visits included a high pressure technology unit of a food industry, an innovation and development department of a food industry, an entrepreneurship centre and a food exhibition. A satisfaction survey was made, through the response of a questionnaire by the students, proving the effectiveness and success of this unit course framework. A SWOT analysis was carried out to gain a better understanding of the strengths, weaknesses, opportunities, and threats involved in the curricular unit objectives.
\end{abstract}

Keywords: Food industry; Satisfaction survey; Food studies

\section{Introduction}

Innovation through the creation and use of knowledge to create value has been recognised as a key driver of economic growth (Winger \& G., 2006). Thus, the characterization of the food industry is important to understand the constraints and challenges to innovation in food en- terprises. Food and drink (for simplicity of language, drink will be included in the term food) industry is the largest manufacturing industry sector $(14.6 \%)$ in the European Union (EU) with a turnover in 2012 of more than $€ 1$ trillion ( $€ 1,048$ billion) and $1.8 \%$ of EU gross value added. The share of the turnover to research 
and development (R\&D) was of only $0.27 \%$ in 2010 (FoodDrinkEurope, 2014). It is a very fragmented sector with 286,000 enterprises and is the largest employer in EU manufacturing industry with 4.24 million people (FoodDrinkEurope, 2014). The number of small and mediumsized enterprises (SMEs), with less than 250 employees, contributes to $99.1 \%$ of total businesses. Sectorially, the smallest percentage is in the dairy product sub-sector $(97.7 \%)$ and the highest percentage in the bakery and flour product sub-sector $(99.6 \%$ ) (FoodDrinkEurope, 2012). Even though there is such a high quantity of SMEs, their contribution to the total food industry turnover has only just the first time in a decade exceeded $50 \%$ (51.6\%) (FoodDrinkEurope, 2014). Though the food sector is the largest sector of manufacturing industry in terms of turnover and value added, when analysing the top 1,000 EU companies, the food industry investment in $\mathrm{R} \& \mathrm{D}$ is the lowest one (€2.2 billion), representing only $1.5 \%$ of the total EU manufacturing industry investment in 2011 (FoodDrinkEurope, 2014)).

Innovation is the application of ideas, technology and processes in novel ways to gain a competitive advantage and create value (Saguy, 2011). Thus, it is now recognized that innovation in SME is both crucial and is a significant challenge (Sarkar \& Costa, 2008). Similarly, internationalization is a significant determinant of innovation (Karantininis, Sauer, \& Furtan, 2010). Knowledge transfer from the research environment to SME in the food producing sector is crucial for competitiveness and even survival (Braun \& Hadwiger, 2011).

From a competitive perspective, the shift from a manufacturing-based to a technology-innovation and knowledge-based economy requires new skills among organizational employees. According to executive staff in enterprises it is known that food engineers and scientists need to be entrepreneurial. As competition and costs rise, research and development efforts must clearly contribute to business growth and the company bottom line. Thus, companies are looking for technical professionals who may generate new ideas and new businesses.

Thus, food innovation and entrepreneurship are important topics in graduate food studies (Earle,
1997; Grunert et al., 2008). Students should be challenged to promote an innovative attitude towards their future career in the food industry sector, as professionals working in a small and medium enterprise, or in a large multinational company, or even as entrepreneurs with their own working project.

The objective of this work is to present a case study of a curriculum unit of a master's degree course that has been designed to integrate innovation and entrepreneurship abilities into food industry sectors with knowledge on new and sustainable technologies and products.

\section{Curriculum unit description}

The annual curriculum unit, named Seminar, integrated in the first year of the master's degree course in Innovation and Entrepreneurship in Food Industry, offered by Viana do Castelo Polytechnic Institute, in Northern Portugal, will be described. This description will focus on the 2012/2013 academic year in which the 15 students who enrolled the master's course came mainly $(67 \%)$ from the bachelor's degree course in Food Engineering run in the same institution; $87 \%$ were women, $20 \%$ were working students and $50 \%$ came directly from a bachelor's degree with no previous professional experience.

The bachelor's degree in Food Engineering, that has 180 ECTS (European Credit Transfer and Accumulation System) in accordance with Bologna process, provides students with a solid training in essential topics for the food industry (Food Processing and Preservation, Process Control, Quality Control, Quality Management, Marketing and New Food Product Development).

The master's course in Innovation and Entrepreneurship in Food Industry with a main scientific area of Food Science \& Technology (FS\&T) has 120 ECTS and semester duration. The program aims to enable students to i) design and develop one product or a food factory in an integrated way, through innovative technologies or processes, considering aspects of health, safety and legislation, together with consumer acceptance issues, and to ii) develop soft skills in research capabilities, scientific and experimental 
maturity that also includes autonomy and team work. The ultimate goal of the master's course of Innovation and Entrepreneurship in Food Industry is to provide engineers, business majors and scientists with the skills and knowledge required to drive innovation in today's collaborative, global workforce, using a combination of class work, case work and real-world project activity.

The first year of the master study cycle, has the Seminar unit spanning two semesters together with single the semester units of Food Quality and Consumer, Food Quality Legislation and Certification, Food Quality and Public Health, Advanced Food Process Engineering, Innovation Project and Management and Business Financing. The second year is dedicated to a research project or training at food enterprises with which Polytechnic Institute maintains good collaborative relationships. The Seminar unit was divided in two main components. The schematic structure of the unit is presented in Figure 1. The first component was dedicated to:

i) visits to food processing industries and packaging suppliers, accompanied by a qualified professional in FS\&T who explained the process,

ii) one-hour seminars on hot topics in FS\&T by invited experts from academia (5 of 11) and industry (6 of 11),

iii) meetings with entrepreneurs, including alumni, who discussed their projects, challenges and difficulties and facilitated exchange of experiences; and a visit to a startup enterprise incubator centre in the region,

iv) a visit to a food industry exhibition to showcase the dynamic of a business platform for the food sector that brings together product launches, new customers and markets, and

v) participation in a conference on training requirements for the food sector, under the auspices of a funded "COMPETE Programa Operacional Fatores de Competitividade" project .
Hot topics included edible films and coatings, bioprocessing, the association of tradition and innovation in high quality food products, new convenience foods, challenge tests, and new clean and sustainable processes (Figure 2). Trips to Food enterprise facilities included visits to a high pressure technology food industry, an innovation and development department of a food ingredient industry, a flexible plastic packaging supplier and an entrepreneurship and incubation centre that promotes and guides innovative business initiatives. Students visited Alimentaria Food Expo in Lisbon in 2013, the biggest business platform for the food, drink, distribution and hospitality sectors in Portugal.

The second main component of the Seminar unit was the development of a literature review of the state-of-the-art about an emergent or novel food technology or product and with a final individual oral presentation. The topics were selected by students and included themes on edible coatings, canning valorisation, probiotics, functional foods, vacuum chilling, case studies of innovative food products, new canning technologies, biofactories, ohmic heating, electric and light pulse technologies. Due to the structure of this curriculum unit, textbooks were not suggested in advance and, instead, the individual student was encouraged to build their own bibliographic search to obtain the latest relevant information. The available resources for bibliographic review (physical library, national catalogue, statistical databases, and online databases such as ISI, Web ok, Knowledge and Scopus) were explained to students, by a specialized personnel from the Documentation and Information Services of the Polytechnic Institute, in order to guide and improve quality of information search procedures. The assessment method was divided into $20 \%$ for participation in seminars and visits, and $80 \%$ for the individual written report.

\section{Student satisfaction questionnaire-based survey}

To assess the student satisfaction about the Seminar unit, a questionnaire-based survey was prepared and students were asked to give their opinion in a 1-5 Likert scale, 1 - very insufficient, 2

\begin{tabular}{l|l|l|l} 
IJFS | October 2015 | Volume 4 & pages 141-147
\end{tabular} 
$144 \mid$ Fonseca et al.

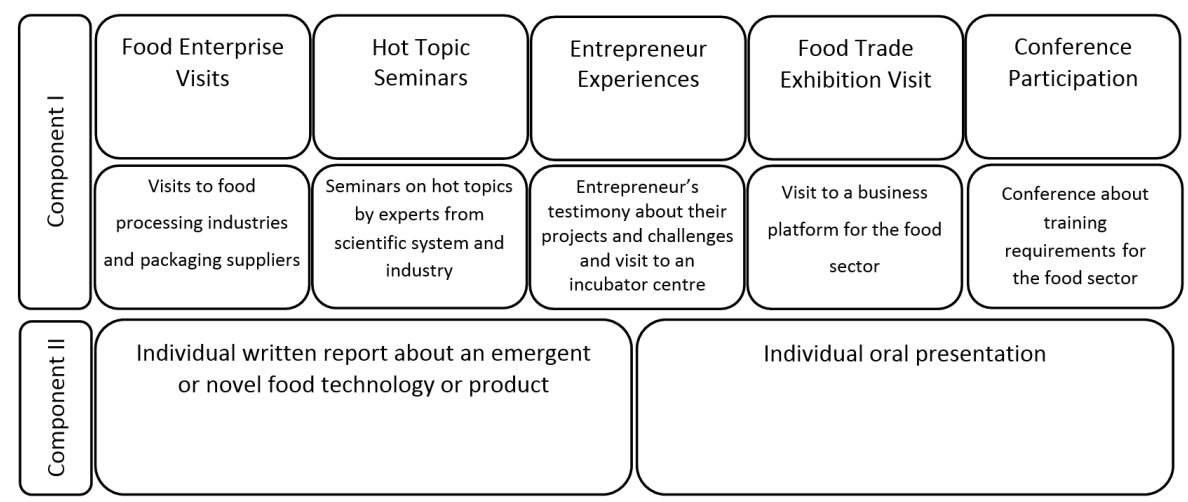

Figure 1: Schematic representation of the curricular unit structure of Seminar

\begin{tabular}{|c|c|c|c|}
\hline & Seminar Theme & Expert from & Title \\
\hline \multirow{5}{*}{ 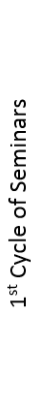 } & Process Innovation & Academia & $\begin{array}{l}\text { Yarrowia lipolytica: a microbial factory to produce interesting } \\
\text { compounds to food industry }\end{array}$ \\
\hline & Process Innovation & Academia & $\begin{array}{l}\text { Films and coatings od edible biopolymers applied to fruit } \\
\text { packaging }\end{array}$ \\
\hline & Process Innovation & Academia & Strategies for improving quality and safety in food processing \\
\hline & $\begin{array}{l}\text { Product Tradition \& } \\
\text { Innovation }\end{array}$ & Industry & High quality products from "Trás-os-Montes" region \\
\hline & $\begin{array}{l}\text { Product Tradition \& } \\
\text { Innovation }\end{array}$ & Industry & Products of excellency in mountain diet \\
\hline \multirow{6}{*}{ 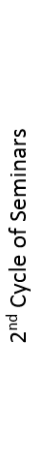 } & Entrepreneurship & Industry & Entrepreneurs in food sector: Meia.duzia enterprise \\
\hline & Entrepreneurship & Industry & Entrepreneurs in food sector: Wedotech enterprise \\
\hline & $\begin{array}{c}\text { Innovation \& } \\
\text { Internationalization }\end{array}$ & Industry & $\begin{array}{l}\text { PortugalFoods: food sector association to promote } \\
\text { Competitiveness and Internationalization }\end{array}$ \\
\hline & $\begin{array}{l}\text { Professional Skills \& } \\
\text { Competences }\end{array}$ & Industry & Skills for employability in food sector \\
\hline & $\begin{array}{l}\text { Process and Product } \\
\text { Innovation }\end{array}$ & Academia & Case studies of innovation in food sector \\
\hline & $\begin{array}{l}\text { Quality and Process } \\
\text { Control }\end{array}$ & Academia & $\begin{array}{l}\text { Challenging tests in process validation and shelf life } \\
\text { determination }\end{array}$ \\
\hline
\end{tabular}

Figure 2: Titles of the hot topic seminars in 2012/2013 under the scope of the curricular unit Seminar 
insufficient, 3- sufficient, 4- good and 5- very good, about the unit's level of general interest, unit relevance to professional future, unit general satisfaction interest in hot topic seminars, interest in entrepreneurship talks, interest in food industry visits, interest in Innovation report and presentation, interest in the food expo visit, the unit's structure, relationship between the unit and innovation, relationship between the unit and entrepreneurship and adequacy of the unit's evaluation method.

The response frequencies to the questionnaire, as percentages, are presented in Fig. 3. A good and very good level of general interest was reported by almost $90 \%$ of students and $67 \%$ considered it relevant for professional future. Approximately $90 \%$ and $78 \%$ of responses were maximum preference for the food industry visits and food expo visit, respectively. This highlights the importance of the contact with the real professional environment. In parallel with this questionnaire, another administered to the master course indicated that the suitability of its practical component was considered adequate by $70 \%$ and very adequate by $20 \%$ of students. There was a very good level of interest on visits to facilities, and the development of a written work based on a solid literature review was very well executed by $56 \%$ students. Hot topic seminars and entrepreneurship talks were held and achieved favourable assessment by $33 \%$ and $67 \%$ of students. The unit structure, the relationship between the unit and entrepreneurship and adequacy of the evaluation method were the factors negatively classified by some $10 \%$ of students.

\section{SWOT analysis}

A SWOT analysis performed on the content and design of the Seminar component and presented in Fig. 4, highlights that students have a good opportunity to come into contact and interact with interesting subjects and with people that may help them consolidate their knowledge and to indicate new opportunities for their future work. This is possible due to the wide range of topics that were presented by experts, the important partnership with food industry, food organizations and official organisms that the Poly- technic Institute has been consolidating over the years, and that made possible the organization of the visits to food factories and food organizations. However the desired outcomes were not always achieved because students did not have enough time to develop and explore the topics. The interaction between students and the lecturers is normally short and limited to the session. Another hurdle was that the local enterprises are general micro enterprises with limited resources and difficulties in receiving students and giving them the opportunity to implement their ideas. Nevertheless, with this Seminar unit students and teachers were exposed to potential new ideas and new working practices. It was also seen as an opportunity for establishing new partnerships to get involved in projects with financial support for new research, development and innovation that may lead to entrepreneur projects.

\section{Recommendations and future work}

This unit structure was first implemented in the 2012/2013 academic year. Future work and recommendations for review are important and should be highlighted.

New topics on consumer insights for new food products, regarding consumer profiling, data mining and new sensory characterization techniques should be explored in later available editions of the unit. The e-revolution presents new challenges to the food sector, such as ecommerce, QR codes and interactive marketing. A continuous effort must be made to ensure that future editions would include the most recent food trends in their topics.

Higher interaction with business incubators centres is very interesting improve knowledge of the motivations of start-up enterprises and the difficulties they face, in entrepreneurship.

A survey of student's satisfaction was presented in this work but it would also be interesting to interview industrial people about the visits and seminars interactions, to project potential for improved employability, meeting industrial expectations and potential future improvement.

The authors intend to contact these students in the near future ( 5 years after) to evaluate the 
$146 \mid$ Fonseca et al.

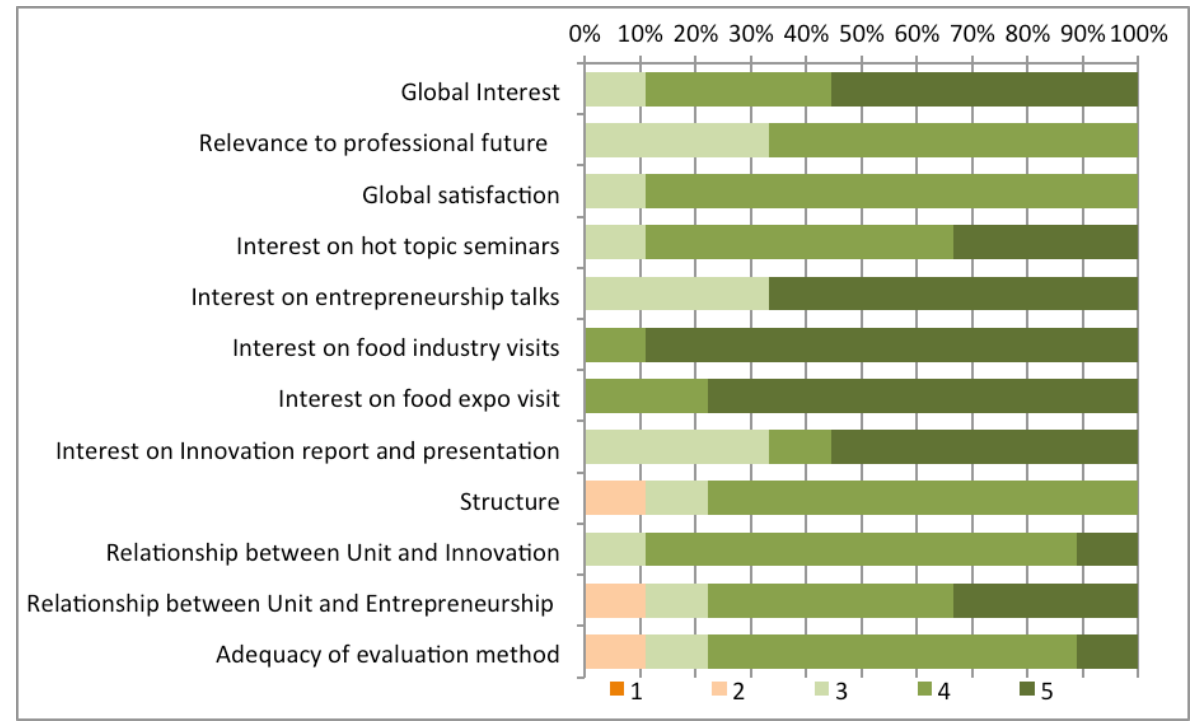

Figure 3: Descriptive analysis of student responses to questionnaire about Seminar unit satisfaction

\begin{tabular}{|c|c|}
\hline $\begin{array}{l}\text { Strengths } \\
\text { - Wide range of up-to-date topics } \\
\text { - Visits to food industry } \\
\text { - Partnership with food industry, food } \\
\text { organisations and official organisms } \\
\text { - Enhancement of industry-academia } \\
\text { relationships and employability }\end{array}$ & $\begin{array}{l}\text { Weaknesses } \\
\text { - Insufficient time to deepen subjects } \\
\text { - Punctual interaction between students and } \\
\text { the invited lecturers } \\
\text { - Scarce financial support to invite foreign } \\
\text { experts }\end{array}$ \\
\hline $\begin{array}{l}\text { Opportunities } \\
\text { - New possibilities for teachers and students } \\
\text { arise with new working lines } \\
\text { - Establishment of new partnerships to get } \\
\text { involved in projects with financial support } \\
\text { for student's research ideas }\end{array}$ & $\begin{array}{ll}\text { Threats } & \\
\text { - Insipient region enterprise network, } \\
\\
\text { underdeveloped and with limited resources }\end{array}$ \\
\hline
\end{tabular}

Figure 4: SWOT analysis to the Seminar unit of the master course in Innovation and Entrepreneurship in Food Industry 
Food innovation and entrepreneurship in high education |147

relevance of this curriculum unit in their professional life.

\section{Conclusions}

The topics on Innovation and Entrepreneurship were developed with success in a curriculum unit of a master's degree course with a strong practical component that included visits to enterprises, seminars, and food expo visits, among other activities. A final validation was made, through the administration of questionnaire to the students, proving the effectiveness of this unit course framework.

\section{Acknowledgements}

The authors wish to acknowledge the contribution of industry professionals who hosted the food industry visits and of colleagues from other institutions of the national scientific system and experts who kindly accepted participate in seminars. The participation of students in the satisfaction survey is also acknowledged.

\section{References}

Braun, S. \& Hadwiger, K. (2011). Knowledge transfer from research to industry (smes) - an example from the food sector. Trends in Food Science 83 Technology, 22(1), S90S96. doi:10.1016/j.tifs.2011.03.005

Earle, M. D. (1997). Innovation in the food industry. Trends in Food Science 83 Technology, 8(5), 166-175. doi:10.1016/S0924-2244(97) 01026-1

FoodDrinkEurope. (2012). Data \& trends of the european food and drink industry. Retrieved from http://www.fooddrinkeurope. $\mathrm{eu} /$ publications/index/

FoodDrinkEurope. (2014). Data \& trends of the european food and drink industry 2013-2014. Retrieved from http://www . fooddrinkeurope.eu/publications/index/
Grunert, K. G., Jensen, B. B., Sonne, A. M., Brunso, K., Byrne, D. V., Clausen, C., ... Scholderer, J. (2008). User-oriented innovation in the food sector: relevant streams of research and an agenda for future work. Trends in Food Science 83 Technology, 19(11, SI), 590-602. doi:10.1016/j. tifs.2008.03.008

Karantininis, K., Sauer, J., \& Furtan, W. H. (2010). Innovation and integration in the agri-food industry. Food Policy, 35(2), 112-120. doi:10.1016/j.foodpol.2009.10.003

Saguy, I. S. (2011). Paradigm shifts in academia and the food industry required to meet innovation challenges. Trends in Food Science $\&_{3}$ Technology, 22 (9, SI), 467-475. International Conference on Food Innovation (Food Innova), Polytechn Univ Valencia, Valencia, SPAIN, OCT 25-29, 2010. doi:10. 1016/j.tifs.2011.04.003

Sarkar, S. \& Costa, A. I. A. (2008). Dynamics of open innovation in the food industry. Trends in Food Science \&3 Technology, 19(11, SI), 574-580. doi: $10.1016 / \mathrm{j}$. tifs . 2008.09.006

Winger, R. \& G., W. (2006). Food product innovation - a background paper. Food and Agriculture Organization of the United $\mathrm{Na}$ tions, Rome. Retrieved from http://www. fao.org/docrep/016/j7193e/j7193e.pdf 